\title{
Differences in Secure Messaging, Self-management, and Glycemic Control Between Rural and Urban Patients: Secondary Data Analysis
}

Stephanie A Robinson ${ }^{1,2}$, PhD; Dane Netherton ${ }^{1}, \mathrm{PhD}$; Mark Zocchi ${ }^{1,3}$, MPH; Carolyn Purington ${ }^{1}$, MPH; Arlene S $\mathrm{Ash}^{4}, \mathrm{PhD}$; Stephanie L Shimada ${ }^{4,5}, \mathrm{PhD}$

\footnotetext{
${ }^{1}$ Center for Healthcare Organization and Implementation Research, VA Bedford Healthcare System, Bedford, MA, United States

${ }^{2}$ The Pulmonary Center, Boston University School of Medicine, Boston, MA, United States

${ }^{3}$ The Heller School for Social Policy and Management, Brandeis University, Waltham, MA, United States

${ }^{4}$ Division of Health Informatics and Implementation Science, Population and Quantitative Health Sciences, University of Massachusetts Medical School, Worcester, MA, United States

${ }^{5}$ Department of Health Law, Policy, and Management, Boston University School of Public Health, Boston, MA, United States
}

\section{Corresponding Author:}

Stephanie A Robinson, $\mathrm{PhD}$

Center for Healthcare Organization and Implementation Research

VA Bedford Healthcare System

Bldg 70

200 Springs Rd

Bedford, MA, 01730

United States

Phone: 15712767178

Email: stephanie.robinson5@va.gov

\section{Abstract}

Background: Rural patients with diabetes have difficulty accessing care and are at higher risk for poor diabetes management. Sustained use of patient portal features such as secure messaging (SM) can provide accessible support for diabetes self-management. Objective: This study explored whether rural patients' self-management and glycemic control was associated with the use of SM.

Methods: This secondary, cross-sectional, mixed methods analysis of 448 veterans with diabetes used stratified random sampling to recruit a diverse sample from the United States (rural vs urban and good vs poor glycemic control). Administrative, clinical, survey, and interview data were used to determine patients' rurality, use of SM, diabetes self-management behaviors, and glycemic control. Moderated mediation analyses assessed these relationships.

Results: The sample was 51\% ( $\mathrm{n}=229)$ rural and 49\% ( $\mathrm{n}=219)$ urban. Mean participant age was 66.4 years (SD 7.7 years). More frequent SM use was associated with better diabetes self-management $(P=.007)$, which was associated with better glycemic control $(P<.001)$. Among rural patients, SM use was indirectly associated with better glycemic control through improved diabetes self-management (95\% CI 0.004-0.927). These effects were not observed among urban veterans with diabetes (95\% CI -1.039 to 0.056$)$. Rural patients were significantly more likely than urban patients to have diabetes-related content in their secure messages $(P=.01)$.

Conclusions: More frequent SM use is associated with engaging in diabetes self-management, which, in turn, is associated with better diabetes control. Among rural patients with diabetes, SM use is indirectly associated with better diabetes control. Frequent patient-team communication through SM about diabetes-related content may help rural patients with diabetes self-management, resulting in better glycemic control.

(JMIR Diabetes 2021;6(4):e32320) doi: $\underline{10.2196 / 32320}$

\section{KEYWORDS}

diabetes; secure messaging; rural; self-management; patient portal; urban; data; access; risk; portal; eHealth; digital health; messaging; support; accessible; cross-sectional; veteran 


\section{Introduction}

\section{Background}

Over 30 million people in the United States have been diagnosed with type 2 diabetes [1]. Poor glycemic control, defined as hemoglobin $\mathrm{A}_{1 \mathrm{c}}\left(\mathrm{HbA}_{1 \mathrm{c}}\right)>8 \%(64 \mathrm{mmol} / \mathrm{mol})$ [2], in patients with type 2 diabetes is a risk factor for the development of diabetes-related complications including retinopathy, neuropathy, heart disease, stroke, blindness, kidney failure, and lower limb amputations [3]. Costs for diabetes care are high and rising [4,5]. Within the United States, total costs have been estimated at US $\$ 465.2$ billion, including morbidity, mortality, and medical costs [6]. Glycemic control is the primary therapeutic objective for the prevention of diabetes-related complications [7].

\section{Diabetes Management in Rural Populations}

Diabetes is a nationwide epidemic, though difficulty managing this complex, chronic condition varies across the United States [8]. Management is markedly more difficult in rural communities with limited access to health information and specialty care $[9,10]$. Diabetes is nearly $10 \%$ more prevalent in rural than in urban areas, likely owing to greater risk factors including lower income, older age, and higher body mass index [11]. In addition, individuals living with diabetes in rural areas face numerous barriers (limited availability of diabetes education [12], reduced cell phone coverage and internet access [13], transportation barriers, and lengthy travel distances $[14,15]$ ), preventing patients from accessing health care [16]. The Veterans' Affairs (VA) Office of Rural Health estimates nearly 5 million veterans live in rural areas where access to care can be difficult [17], and that almost $40 \%$ of Veterans Health Administration (VHA) patients with diabetes live in rural areas [18].

\section{Promise of Patient Portals}

Diabetes self-management behaviors (eg, medication adherence, diet, physical activity, and monitoring blood glucose levels [19]) are consistently linked to achieving glycemic control. Accessible communication, via face-to-face visits or technology, with providers is essential to foster patients' disease self-management [20]. Access to diabetes self-management education and ongoing support can be improved by using digital health solutions [21]. Previous research highlights the benefits of using web-based patient portals, suggesting that increased access to information and support may engage patients in the management of their disease and improve health outcomes [22,23]. Considering the access challenges rural patients face, virtual care services may be even more critical in this population for effective diabetes self-management. Features such as secure messaging (SM) in the VHA web-based patient portal My HealtheVet (MHV), are fundamental to the goal of increasing access to care. SM can be used in lieu of telephone or in-person visits, or to provide additional opportunities for patient-provider communication between visits. Previous coding of SM content revealed wide variety in how it is used, including self-management behaviors such as medication renewal/refill requests, scheduling, referrals, and discussing medication or health issues [24,25].
Research to date suggests that SM use is associated with higher odds of meeting $\mathrm{HbA}_{1 \mathrm{c}}$ control targets, with increased odds of control for every additional message sent per year [26], and with more years of use [27]. SM use may support improved diabetes self-management, though the exact mechanism among these 3 constructs has not been established. It is also unclear to what extent patient characteristics, such as where they live, may play a role in the effectiveness of SM. SM is potentially more beneficial for rural patients with reduced access to in-person care, though it is also possible that it may be less helpful or accessible for those in rural areas with more limited internet access [28-30].

\section{This Study}

This study examined and compared the benefits of sustained SM use for rural and urban patients with diabetes. Rural patients with diabetes are less likely to engage in self-management behaviors, have worse glycemic control, and more limited access to health care. Therefore, they may depend more on accessible communication to help manage their disease. This study uses a framework that was initially developed to evaluate how the BlueButton within the MHV patient portal can support key stakeholder (eg, patients') experiences, processes of care (eg, patient-team communication, self-management, and care coordination), and health outcomes, and understanding how contextual characteristics (eg, environment or setting in which patients seek and receive health care) shape use of the technology [31]. We have adapted this framework to evaluate other MHV features including SM.

This study had 3 objectives. We sought to investigate whether diabetes self-management mediates the relationship between SM use and glycemic control (objective 1). Additionally, we sought to understand if this mediation was conditional on the patient's environment (eg, where the patient lived; objective 2). Finally, we wanted to understand how patients are using SM for diabetes management (objective 3).

\section{Methods}

\section{Study Design and Recruitment}

This retrospective observational, cohort, sequential, explanatory, mixed methods (QUAN qual) study included US veterans living with type 2 diabetes. Table 1 specifies the timeline and sources of sampling and data collection. All participants experienced uncontrolled diabetes in 2012 (defined as mean $\mathrm{HbA}_{1 \mathrm{c}}>8.0 \%$ and less than $25 \%$ of the year with an $\mathrm{HbA}_{1 \mathrm{c}}<8.0 \%$ ). All participants were sustained users of MHV between 2013 and 2017, defined as having used the portal repeatedly (used prescription refills, viewed or downloaded their health information, and used SM at least twice a year for 2 years between 2013 and 2015) and recently (sent at least 4 SMs between January 2016 and June 2017). Seeking a diverse sample of users who were either in good or poor control of their $\mathrm{HbA}_{1 \mathrm{c}}$, we randomly selected a sample of 500 patients who had achieved good $\mathrm{HbA}_{1 \mathrm{c}}$ control in 2016 (defined as mean $\mathrm{HbA}_{1 \mathrm{c}}<8.0 \%$ for $75 \%$ of the year or more) and 500 who remained in poor $\mathrm{HbA}_{1 \mathrm{c}}$ control in 2016 (defined as mean 
$\mathrm{HbA}_{1 \mathrm{c}}>8.0 \%$ for $75 \%$ of the year or more). We mailed the randomly selected participants $(\mathrm{N}=1000)$ surveys in November 2017, and an additional 200 surveys at the beginning of 2018.

Quantitative methods were used to examine the associations among SM use in 2017, diabetes self-management between November 2017 and February 2018, mean glycemic control in 2018, and differences between rural and urban patients. Data on patients' use of the MHV patient portal, their glycemic control, in-person health care utilization, and demographic variables were obtained from the VHA Corporate Data Warehouse (CDW) and merged with survey responses.

Qualitative methods were used to further understand how participants were using SM for diabetes self-management. Purposeful sampling was used to identify 40 survey respondents to participate in semistructured interviews about their diabetes management and technology use. In the survey, participants were asked an open-ended survey question, "Can you tell us about an 'A-Ha!' Moment when you realized you could use the MHV portal to better manage your diabetes?" We selected interviewees to represent a variety of responses to this and other survey items about MHV use, including those who used a variety of MHV portal features, those with controlled and uncontrolled diabetes, urban and rural patients, and those with or without comorbid mental health diagnoses. Women and minority veterans were oversampled to broaden the representation of patient demographics. More details regarding our survey sampling methodology [25] and qualitative sampling methodology [32] are available elsewhere. This study was approved by the local institutional review board.

Table 1. Study timeline and data sources.

\begin{tabular}{|c|c|c|c|c|c|}
\hline Year & Sampling: diabetes control & Sampling: portal use & $\begin{array}{l}\text { Mixed methods data } \\
\text { sources }\end{array}$ & Constructs (source) & Covariates (source) \\
\hline 2012 & $100 \%$ Uncontrolled diabetes & Repeated portal use ${ }^{\mathrm{a}}$ & $-^{b}$ & - & - \\
\hline 2013 & - & Repeated portal use $\mathrm{a}^{\mathrm{a}}$ & - & - & - \\
\hline 2014 & - & Repeated portal use ${ }^{a}$ & - & - & - \\
\hline 2015 & - & Repeated portal use ${ }^{a}$ & - & - & - \\
\hline 2016 & $\begin{array}{l}50 \% \text { Achieved control } / 50 \% \\
\text { remained uncontrolled }\end{array}$ & Current portal use $\mathrm{e}^{\mathrm{c}}$ & - & - & - \\
\hline 2017 & - & Current portal use ${ }^{c}$ & $\begin{array}{l}\text { - Quantitative: sur- } \\
\text { vey }{ }^{\mathrm{d}} \\
\text { - } \\
\text { Quantitative: corpo- } \\
\text { rate Data Ware- } \\
\text { house (CDW) }\end{array}$ & $\begin{array}{ll}- & \text { Rurality (CDW) } \\
- & \text { SM use (CDW) } \\
- & \text { Diabetes self-man- } \\
& \text { agement (Survey) }\end{array}$ & $\begin{array}{ll}\text { - } & \text { In-person health } \\
\text { care Utilization } \\
\text { (CDW) } \\
\text { - } & \text { Income (survey) } \\
\text { - } & \text { Race (survey) }\end{array}$ \\
\hline 2018 & - & - & $\begin{array}{l}\text { Qualitative: semistruc- } \\
\text { tured interviews }\end{array}$ & $\begin{array}{l}\text { Hemoglobin } \mathrm{A}_{1 \mathrm{c}} \% \text { time } \\
\text { in control }(\mathrm{CDW})\end{array}$ & - \\
\hline
\end{tabular}

\footnotetext{
${ }^{\mathrm{a}}$ Defined as having used prescription refills, having viewed or downloaded their health information, and having used secure messaging at least twice a year for 2 years between 2013 and 2015.

b_: Not available.

${ }^{\mathrm{c}}$ Defined as having sent at least 4 secure messages between January 2016 and June 2017.

${ }^{\mathrm{d}}$ Disseminated at the end of 2017 or in early 2018.
}

\section{Measures}

\section{Rurality}

We identified rurality on the basis of zip codes recorded in the patient's address data from the CDW. The VA uses the Rural-Urban Commuting Areas (RUCA) system to define patient residence as either urban (at least $30 \%$ of the population residing in an urbanized area as defined by the Census Bureau), highly rural (less than $10 \%$ commutes to any community larger than an urbanized cluster), or rural (land areas not defined as urban or highly rural). RUCA codes are created using a validated algorithm developed by the US Department of Agriculture-Economic Research Service to classify US census tracts using measures of population density, urbanization, and daily commuting [33]. Patients who live in rural and highly rural areas were combined and categorized as "rural." Living in a rural area was assigned a value of 0 and living in an urban area was assigned a value of 1 .

\section{$S M$}

Patients' use of SM was quantified in 2017, the year prior to survey data collection, to enable us to evaluate the association between SM use (in 2017) and subsequent diabetes management (in late 2017/early 2018) and glycemic control (in 2018). We counted how many months of the year a patient sent at least one SM. SM use had a possible range of 0 to 12 , where 0 reflected no months of SM use, and 12 reflected sending at least one secure message every month of the year.

To further understand patients' use of SM, we coded the qualitative content of each SM in accordance with published coding methods [34], which have previously been used to code SM [24]. In addition, we coded each message using binary 
indicators for whether the messages were related to each of the following health topics: diabetes-related content, blood pressure, cholesterol, physical activity, diet/nutrition, and mental health. All messages were double-coded by 2 of 3 trained research team members who met regularly to discuss questions, reach agreement on any coding discrepancies, and refine the coding categories. Message codes were collapsed at the thread; that is, if a patient engaged in at least one message about diabetes, the entire message thread was coded as such. Patients were coded as having either engaged in at least 1 thread about a health topic or none. Additionally, as part of the larger study, we conducted qualitative interviews with 40 of the survey respondents [32]. We examined these interviews to further understand rural patient's perceptions and use of SM.

\section{Diabetes Self-management}

Diabetes self-management behaviors were measured with the Diabetes Self-Management Questionnaire (DSMQ) [35]. The DSMQ is a global measure of diabetes self-management comprising 16 items to assess activities related to glycemic control in patients with diabetes (eg, "I strictly follow the dietary recommendations given by my doctor or diabetes specialist"; "I do regular physical activity to achieve optimal blood sugar levels"; and "I keep all of my doctors' appointments recommended for my diabetes treatment"). The questionnaire asks participants to rate each item on a scale from 0 (does not apply to me) to 3 (applies to me very much). From the 16 items, a composite score was calculated as the average of 4 subscales, including glucose management, dietary control, physical activity, and health care use, and could range from 0 to 10 . Higher values indicate greater engagement in self-management. The DSMQ has been shown to be significantly correlated with $\mathrm{HbA}_{1 \mathrm{c}}$ levels [35].

\section{Glycemic Control}

Glycemic control was defined as the estimated percentage of time in control (TIC) over the course of 2018 based on $\mathrm{HbA}_{1 \mathrm{c}}$ measurements ( $\mathrm{A}_{1 \mathrm{c}} \% \mathrm{TIC}$ ). Patients' $\mathrm{HbA}_{1 \mathrm{c}}$ measurements for 2018 were obtained from the CDW. We calculated $\mathrm{A}_{1 \mathrm{c}} \% \mathrm{TIC}$ using the Rosendaal method [36], using linear interpolation to assign a value to each day between patient's successive $\mathrm{HbA}_{1 \mathrm{c}}$ measurements. After interpolation, the percentage of 2018 during which the interpolated $\mathrm{HbA}_{1 \mathrm{c}}$ values within the region of control (ie, $\mathrm{HbA}_{1 \mathrm{c}}<8.0 \%$ ) were calculated.

\section{Covariates}

Covariates included age (measured in years), annual income in late 2017 or early 2018, and in-person health care utilization in 2017. Annual income was self-reported on a 16-category scale ranging from less than US $\$ 5000$ to more than US $\$ 150,000$. We dichotomized annual income using a median split of less than US $\$ 35,000$ (46\% of the sample) and US $\$ 35,000$ or more $(53.6 \%)$. The number of days a patient had a VA primary care visit in 2017 was used to measure in-person health care utilization.

\section{Analyses}

We performed 2-tailed $t$ tests, chi-square tests, and correlation analyses to examine differences between rural and urban participants and relationships between covariates and model measures. Moderated mediation was used to address the first 2 study objectives. Moderated mediation (Figure 1) estimates the indirect effect ( $\mathrm{SM}$ use on $\mathrm{A}_{1 \mathrm{c}} \% \mathrm{TIC}$ through diabetes self-management; research objective 1), and whether this indirect effect is conditional on values of a moderator (rurality; research objective 2). Analyses were conducted using Hayes' PROCESS model in the SAS Enterprise Guide [37]. Moderation of the mediation model by rurality was assessed by calculating the index of moderated mediation [38] between rurality and the indirect effect between SM months in 2017 and $\mathrm{A}_{1 \mathrm{c}} \%$ TIC in 2018. The index of moderated mediation with a dichotomous moderator is defined as the difference in the indirect effects, or mediated effects, between the 2 levels of the moderator (rural and urban). The test of this index is assessed by generating a bootstrap $95 \% \mathrm{CI}$ of the difference in indirect effects across moderator groups. Effects were considered significant if the 95\% CI did not include $0.00(P<.05)$. Qualitative analysis of the SM was used to further understand the nature of the secure message content and patient perceptions of SM (research objective 3 ).

Figure 1. Moderated mediation between secure messaging (SM) use in 2017 and percent time in control of hemoglobin $\mathrm{A}_{1 \mathrm{c}}$ in 2018 ( $\mathrm{A}_{1 \mathrm{c}} \% \mathrm{TIC}$ ), via diabetes self-management, moderated by rurality. Numbers represent parameter estimates. Model adjusts for age, gender, and income. $* 95 \% \mathrm{CI}$ does not include 0.00 and $P<.05$.

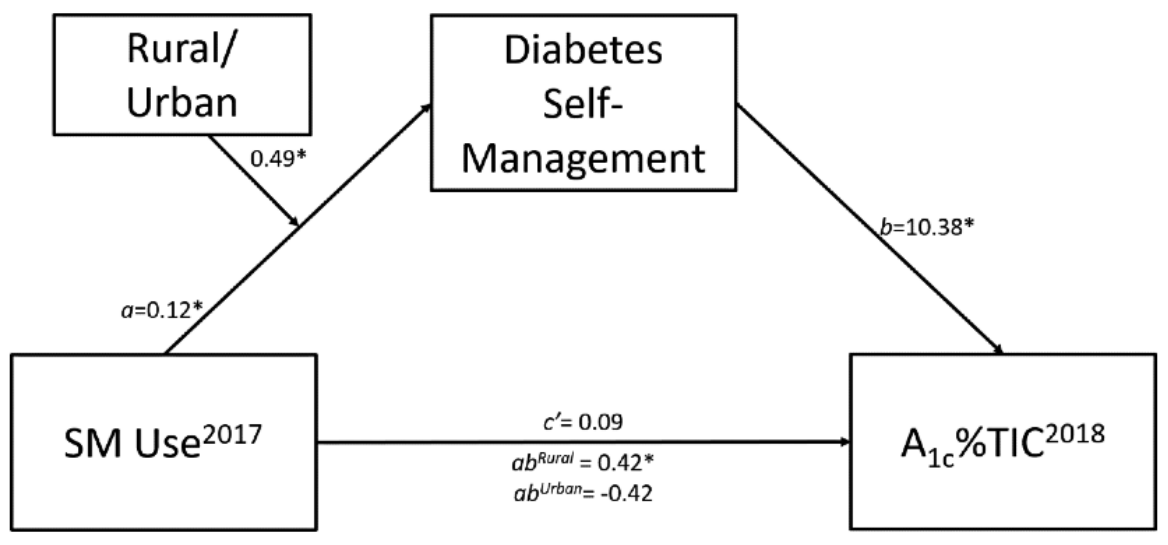




\section{Results}

We mailed 1200 surveys and received 448 (37\%) responses. Table 2 describes the respondent sample in 2017, of whom just over half $(51 \%)$ lived in rural areas. Most $(94 \%)$ were male, and just over half (54\%) reported an annual income above US $\$ 35,000$. The mean age of survey respondents was 66.4 years (SD 7.5 years, range 34-88 years). In-person health care utilization ranged from 0 to 54 in-person visits; $52 \%(n=231)$ of the sample had 8 (median) or fewer in-person visits. As a population, they spent approximately half of their time in control in 2018 (mean $\mathrm{A}_{1 \mathrm{c}} \% \mathrm{TIC} 52.6 \%$, SD 43.6\%, range 0\%-100\%). Their use of SM ranged from 0 to 12 months (mean 6.7 months, SD 3.1 months) in 2017. On average, patients reported relatively high levels of diabetes self-management (mean 7.9, SD 0.9, range 5.5-9.5). Rural and urban veterans were similar in income, age, $\mathrm{A}_{1 \mathrm{c}} \% \mathrm{TIC}$, in-person health care utilization, diabetes self-management score, and number of months using SM. SM use was significantly correlated with more in-person health care utilization ( $r=0.7, P<.001)$. Diabetes self-management was significantly correlated with a higher $\mathrm{A}_{1 \mathrm{c}} \% \mathrm{TIC}$ in 2018 ( $r=0.21$, $P<.001)$.

Table 2. Respondent characteristics by rurality $(\mathrm{N}=446)$.

\begin{tabular}{lllll}
\hline Characteristics & All & Rural (n=228) & Urban (n=218) & $P$ value $^{\mathrm{a}}$ \\
\hline Male, $\mathrm{n}(\%)$ & $418(94)$ & $214\left(94^{\mathrm{b}}\right)$ & $204\left(94^{\mathrm{c}}\right)$ & 0.90 \\
Income $<\mathrm{US} \$ 35,000, \mathrm{n}(\%)^{\mathrm{d}}$ & $207(46)$ & $111\left(49^{\mathrm{b}}\right)$ & $96\left(44^{\mathrm{c}}\right)$ & 0.33 \\
Age, mean (SD) & $66.4(7.5)$ & $66.3(7.3)$ & $66.5(7.7)$ & 0.82 \\
2017 In-person primary care visits, mean (SD) & $10.1(7.8)$ & $9.5(7.0)$ & $10.6(9.5)$ & 0.12 \\
\hline
\end{tabular}

${ }^{\mathrm{a}}$ Rural vs urban respondents.

${ }^{b}$ Percentage values are based on a total value of 228 respondents.

${ }^{\mathrm{c}}$ Percentage values are based on a total value of 218 respondents.

${ }^{\mathrm{d}}$ Income from the survey was for late 2017 or early 2018 based on when respondents completed their survey.

\section{Diabetes Self-management}

More months using SM was significantly and positively associated with greater diabetes self-management $(B=0.12,95 \%$ CI 0.033-0.212; $P=.007 ; a$ in Figure 1). Rurality influenced the strength of the relationship between SM use and diabetes self-management $(B=-0.08,95 \% \mathrm{CI}-0.138$ to $-0.026 ; P=.005)$. When we examined the conditional effects of SM on diabetes self-management for rurality, there was a trend to a significant positive relationship between SM and diabetes self-management for rural patients $(B=0.04,95 \% \mathrm{CI}-0.001$ to $0.083 ; P=.06)$ and a trend toward a negative relationship between SM and diabetes self-management among urban patients $(B=-0.04,95 \% \mathrm{CI}$ -0.080 to $0.002 ; P=.06)$.

\section{Glycemic Control}

Patients who reported greater diabetes self-management had significantly higher $\mathrm{A}_{1 \mathrm{c}} \% \mathrm{TIC}$ (ie, more time in control of their diabetes throughout the year; $B=10.38,95 \%$ CI 5.539-15.217; $P<.001 ; b$ in Figure 1). There was no direct effect of SM use on $\mathrm{A}_{1 \mathrm{c}} \%$ TIC $\left(B=0.09,95 \% \mathrm{CI}-1.463\right.$ to $1.651 ; P=.91$; $c^{\prime}$ in Figure 1). However, there was a conditional indirect effect between SM use and $\mathrm{A}_{1 \mathrm{c}} \% \mathrm{TIC}$, via diabetes self-management for rural patients $(B=0.42$, 95\% CI 0.004-0.927; Table 3 and $a b^{\text {Rural }}$ in Figure 1). This conditional indirect effect represents the change in $\mathrm{A}_{1 \mathrm{c}} \% \mathrm{TIC}$ for every month of SM use, mediated by diabetes self-management. Among urban patients, there was no indirect effect between $\mathrm{SM}$ use and $\mathrm{A}_{1 \mathrm{c}} \% \mathrm{TIC}$ via self-management $\left(B=-0.42,95 \% \mathrm{CI}-1.039\right.$ to $0.056 ; a b^{\text {Urban }}$ in Figure 1). The index of moderated mediation (ie, the difference between rural and urban indirect effects) was significant (index $=-0.85,95 \% \mathrm{CI}-1.64$ to -0.23 ). 
Table 3. Moderated mediation analyses.

\begin{tabular}{|c|c|c|}
\hline & $B(95 \% \mathrm{CI})$ & $P$ value \\
\hline \multicolumn{3}{|l|}{ Model to predict diabetes self-management } \\
\hline Constant & $5.81(4.82$ to 6.81$)$ & $<.001$ \\
\hline Secure messaging use during 2017 & $0.12(0.03$ to 0.21$)$ & .007 \\
\hline Rurality & $0.49(0.08$ to 0.90$)$ & .02 \\
\hline Secure messaging use during $2017 *$ Rurality & $-0.08(-0.13$ to -0.03$)$ & .005 \\
\hline Secure messaging use during $2017 *$ Rural & 0.04 (0.00 to 0.08$)$ & .06 \\
\hline Secure messaging use during $2017 *$ Urban & $-0.04(-0.08$ to 0.00$)$ & .06 \\
\hline Age & $0.02(0.01$ to 0.03$)$ & .003 \\
\hline In-person primary care visits in 2017 & $0.01(-0.01$ to 0.02$)$ & .29 \\
\hline Income $($ reference $=<$ US $\$ 35,000)$ & $0.16(-0.01$ to 0.34$)$ & .08 \\
\hline \multicolumn{3}{|l|}{ Model to predict the percent time in control of hemoglobin $A_{1 c}$ in 2018} \\
\hline Constant & $-19.13(-69.74$ to 31.49$)$ & .46 \\
\hline $\begin{array}{l}\text { Direct effect of secure messaging use during } 2017 \text { on the percent time in control of hemoglobin } A_{1 c} \text { in } \\
2018\end{array}$ & $0.09(-1.46$ to 1.65$)$ & .91 \\
\hline Diabetes self-management & $10.38(5.54$ to 15.22$)$ & $<.001$ \\
\hline Age & $-0.17(-0.75$ to 0.41$)$ & .56 \\
\hline In-person primary care visits in 2017 & $0.11(-10.70$ to 6.72$)$ & .65 \\
\hline Income $($ reference $=<$ US $\$ 35,000)$ & $-1.99(-10.70$ to 6.72$)$ & .65 \\
\hline \multicolumn{3}{|l|}{ Indirect effects of Rurality on the percent time in control of hemoglobin $A_{1 c}$ in 2018} \\
\hline Rural & $0.42(0.01$ to 0.92$)$ & $-^{\mathrm{a}}$ \\
\hline Urban & $-0.42(-1.03$ to 0.05$)$ & - \\
\hline
\end{tabular}

a__: not determined.

\section{Sensitivity Analysis}

This study modeled SM use in 2017 and $\mathrm{A}_{1 \mathrm{c}} \%$ TIC in 2018. Had we examined both SM use and glycemic control in the same year, we would have risked potentially having some participants with SM data toward the end of the year and $\mathrm{HbA}_{1 \mathrm{c}}$ measurements in the beginning of the year. These data would not be consistent with the hypothesized temporal nature of the analysis. However, as sensitivity analysis, we compared SM use in 2017 and 2018. SM use in 2017 and 2018 were significantly correlated $(r=0.53, P<.001)$. Additionally, we ran the moderated mediation model using both SM use and $\mathrm{A}_{1 \mathrm{c}} \% \mathrm{TIC}$ in 2018. A similar pattern of results occurred in a moderated mediation analysis that examined both SM use and $\mathrm{A}_{1 \mathrm{c}} \% \mathrm{TIC}$ simultaneously in 2018. Further information is included in Multimedia Appendix 1.

\section{SM Content}

Qualitative analysis of the SM content revealed that significantly more rural participants $(77 \%, \mathrm{n}=177)$ discussed diabetes-related content in at least one SM thread than urban participants $(67 \%$, $\mathrm{n}=146 ; P=.01)$. There were no other significant differences between the proportion of urban and rural participants who engaged in at least one thread related to other health topics codes. Semistructured interviews with a subset of survey respondents further expanded on how rural patients perceived SM and were using SM (Table 4). Patients consistently expressed how SM helped them communicate with their clinical teams. Rural patients indicated that SM was a convenient tool to support tasks pertinent to effective diabetes self-management. For example, one patient reported that SM was a more reliable form of communication than through a cell phone to set up appointments or medication renewal requests. Patients also indicated they were able to use SM to communicate their diabetes-related equipment needs with their clinical team. Patients also reported that SM allowed them to communicate with various members of their clinical team. 
Table 4. Qualitative themes and representative quotes.

\begin{tabular}{ll}
\hline Communication theme & Quote \\
\hline Reliability & $\begin{array}{l}\text { Cellphones don't work real [sic] well around here, you have to be in certain areas. There's lots of dead } \\
\text { spots, like hundreds of miles of it...It works better for [hospital] to use secure messaging to set up ap- } \\
\text { pointments. I've used them to talk to [the clinic], I've used them to talk to my provider a couple of times } \\
\text { when I needed prescriptions changed or stuff like that. [Rural male, } 69 \text { years] }\end{array}$
\end{tabular}

Communicate needs rapidly

I've got central tremors and...I'm shaking and I can't get the syringe in the bottle you know. So I just sen[t]... a SM. I said Dr. [name] I want to get pens again I can't do it. Within 48 hours, I'm serious, literally. I had pens delivered to my front door you know. Just absolutely wonderful as far as I'm concerned. [Rural male, 54 years]

Facilitates communication with team

Once I tried to message them or if I sent a message to the nursing staff then the next time I got on there, there was a connection for me to, you know, to send a message directly to my pharmacist... [Rural female, 65 years]

\section{Discussion}

\section{Principal Findings}

In a population of veterans with diabetes, we examined the relationship between the use of SM and percent time in glycemic control, whether diabetes self-management behaviors mediated this relationship, and if the use of SM is beneficial for those both living in urban and rural areas. This study leveraged mixed methods to quantify these relationships through a moderated mediation analysis, examine how patients with diabetes use SM through a message content analysis, and learn from patients through qualitative interviews. Moderated mediation analysis revealed that the relationship between the use of SM, diabetes self-management, and $\mathrm{A}_{1 \mathrm{c}} \%$ TIC was influenced by rurality. Among rural patients, increased use of SM was associated with a higher $\mathrm{A}_{1 \mathrm{c}} \% \mathrm{TIC}$ through diabetes self-management. The mediation of SM and $\mathrm{A}_{1 \mathrm{c}} \% \mathrm{TIC}$ through diabetes self-management was not found among urban patients. This finding does not indicate that SM is not necessarily beneficial for urban patients; rather, it indicates that SM may help support rural patients' diabetes self-management efforts to a greater extent than among urban patients. In addition to the challenges of effective diabetes management, rural patients face additional barriers including limited access to diabetes education and clinical services, limited cell phone coverage and internet access, limited transportation, and long travel distances [39]. It is possible that the enhanced clinical access afforded by SM may not influence self-management among urban patients who do not face the same access barriers as their rural counterparts [10]. SM offers rural patients means to overcome many of these barriers.

Our quantitative analysis included all SM communication (ie, not just diabetes-specific SM) as many different subjects, such as messages about hypertension or physical activity, are likely to be helpful for diabetes management. We used qualitative analyses to further explore the ways in which rural patients leverage SM for diabetes self-management. Rural patients were more likely than their urban counterparts to communicate via SM with their health care team about diabetes-related content, which may be associated with more effective diabetes management efforts. While messages about other health topics may be just as important for diabetes management, there were no significant differences in the frequency in which these other health topics were discussed between rural and urban patients.
Additionally, participant interviews revealed insights into some of the benefits SM affords rural participants, such as SM being a more reliable and convenient means to communicate with various members of their clinical team to engage in activities important for diabetes management (eg, appointment requests, medication renewals, and equipment requests).

This relationship between increased health care team access and greater self-management aligns with previous research; a systematic review evaluating technology-enabled diabetes self-management support concluded that 2-way communication between the patient and clinical team was an essential component for improved $\mathrm{HbA}_{1 \mathrm{c}}$ [40]. Patients who use web-based portals and SM can communicate with their team more regularly, as needed, and potentially reduce the need for in-person visits. Reports on the relationship between SM and in-person health care utilization are inconsistent. For example, we found that greater use of SM was positively associated with more in-person health care utilization, whereas other recent work has found that use of SM was associated with a decrease in in-person utilization [41]. It is difficult to disentangle if patients are using SM in place of in-person care, or if they are using SM because of an upcoming or recent in-person visit (eg, following up on a new medication). Owing to this potential confounder, we included in-person primary care visits as a covariate in our model to control for health care utilization and possible confounding by indication.

\section{Implications}

More consistent use of SM, particularly SM related to diabetes, can help overcome commonly reported regional disparities in diabetes self-management and glycemic control. Despite the benefits of SM for diabetes self-management and glycemic control in rural veterans with diabetes, rural patients are less likely to manage personal health information on the internet or communicate through the internet with their providers [30]. External support from a patient's clinical team has been identified as a key facilitator of diabetes self-management [39], though such support is less available for patients with limited access to in-person visits. Fortunately, virtual modalities such as web-based patient portals and features including SM can provide easily accessible support for effective diabetes self-management. It is critical to identify methods that will promote patients' use of web-based portals for better chronic disease management. Technology-based approaches and interventions are widely accepted for promoting diabetes 
self-management in rural communities [42]. Additionally, we previously found that as little as one team-initiated secure message was significantly associated with better diabetes self-management [25]. Providers may find that encouraging patients, particularly rural patients, to use SM may significantly improve their diabetes self-management and outcomes.

SM has the potential to reach an ever-increasing number of patients. As of July 2021, 3.7 million veterans (more than half of active VA patients) were registered portal users, of which 1.4 million were active users of SM. Increasing SM use can be considered a high-reach, light-touch intervention with the potential to improve population health. Understanding the benefits of modalities that can provide more accessible diabetes self-management support not only has implications for rural patients who typically face barriers accessing in-person health care owing to long travel distances - these findings also support the value of encouraging SM use when in-person visits are not feasible. During the COVID-19 pandemic, VA facilities were directed to convert in-person to virtual care whenever clinically appropriate [43] and for rural patients in particular [44]. Use of SM can help maintain patient-provider communication and support disease self-management when patients cannot access in-person care. Emerging evidence suggests that disparities in rural patients' access to telemedicine, including video visits and portals, have persisted despite dramatic increases in adoption [45]. Our findings suggest that efforts to reduce these disparities are important not only to improve equity but also to support improved outcomes.

\section{Limitations and Future Directions}

This study has some limitations. For one, this sample purposively surveyed patients who were both recent and repeated users of patient portals; it does not speak to the potential benefit of SM in those who have never used portals.
Those who responded to our study may, as a group, have had better self-management than the average patient with diabetes. Indeed, our sample scored higher on the DSMQ than other populations, though not outside the SD [35]. Similarly, as is common in many US Veteran studies, our sample size was mostly male, which limits the potential generalizability of these findings to females and non-Veterans.

The current analysis examined self-management as a composite score. Future research may examine the relationship between SM use and various self-management behaviors, and if certain self-management behaviors are more important in the relationship between SM use and $\mathrm{A}_{1 \mathrm{c}} \%$ TIC. Finally, another limitation is the cross-sectional and observational nature of the study. Our mediation model allows us to begin to think about the causal nature of these relationships. Future studies might benefit from interventional designs that examine changes to diabetes self-management and glycemic control after initiating SM use compared to a sample who have never used SM.

\section{Conclusions}

On average, patients with diabetes who live in rural areas are disproportionately affected by diabetes, in part owing to their limited access to health care. Among rural patients, greater use of SM was associated with better diabetes self-management, which was associated with better glycemic control. This was not observed among urban patients. Rural patients with diabetes may benefit significantly from using SM to support their diabetes self-management and diabetes-related outcomes. Encouraging patients to ask questions between visits, or reaching out to them directly via SM, are examples of light-touch interventions with potential to improve outcomes for millions of patients with diabetes who lack ready access to in-person care.

\section{Acknowledgments}

This study was financially supported by the Department of Veterans Affairs, Veterans Health Administration, Office of Research and Development, Health Services Research, and Development Service (IIR 15-307). The writing of this manuscript was financially supported by the Department of Veterans Affairs Office of Academic Affiliations Advanced Fellowship Program in Health Services Research and the National Heart, Lung, and Blood Institute (K12HL138049). Dr Robinson was involved in the analysis and interpretation of data. Dr Netherton, Mr Zocchi, and Mrs Purington contributed to the acquisition and analysis of the data. Dr Ash contributed to the analysis and interpretation of the data. Dr Shimada contributed to the conception of the project, and analysis and interpretation of the data. All authors contributed to drafting the work, final approval, and agree to be accountable for all aspects of the work.

\section{Conflicts of Interest}

None declared

\section{Multimedia Appendix 1}

Supplementary sensitivity analysis.

[DOCX File, 18 KB-Multimedia Appendix 1]

\section{References}

1. National Diabetes Statistics Report, 2017: Estimates of Diabetes and Its Burden in the United States. Centers for Disease Control and Prevention. URL: https://dev.diabetes.org/sites/default/files/2019-06/cdc-statistics-report-2017.pdf [accessed 2021-11-04] 
2. American Diabetes Association. 6. Glycemic Targets:. Diabetes Care 2018 Jan;41(Suppl 1):S55-S64. [doi: 10.2337/dc18-S006] [Medline: 29222377]

3. American Diabetes Association. Standards of Medical Care in Diabetes-2016 Abridged for Primary Care Providers. Clin Diabetes 2016 Jan;34(1):3-21 [FREE Full text] [doi: 10.2337/diaclin.34.1.3] [Medline: 26807004]

4. Seaquist ER. Addressing the burden of diabetes. JAMA 2014 Jun 11;311(22):2267-2268. [doi: 10.1001/jama.2014.6451] [Medline: 24915253]

5. Zhuo X, Zhang P, Hoerger TJ. Lifetime direct medical costs of treating type 2 diabetes and diabetic complications. Am J Prev Med 2013 Sep;45(3):253-261. [doi: 10.1016/j.amepre.2013.04.017] [Medline: 23953350]

6. Shrestha SS, Honeycutt AA, Yang W, Zhang P, Khavjou OA, Poehler DC, et al. Economic Costs Attributable to Diabetes in Each U.S. State. Diabetes Care 2018 Dec;41(12):2526-2534. [doi: 10.2337/dc18-1179] [Medline: 30305349]

7. Koro C, Bowlin S, Bourgeois N, Fedder D. Glycemic control from 1988 to 2000 among U.S. adults diagnosed with type 2 diabetes: a preliminary report. Diabetes Care 2004 Jan;27(1):17-20. [doi: 10.2337/diacare.27.1.17] [Medline: 14693960]

8. Frieden TR, Centers for Disease ControlPrevention (CDC). CDC Health Disparities and Inequalities Report - United States, 2013. Foreword. MMWR Suppl 2013 Nov 22;62(3):1-2. [Medline: 24264482]

9. Lutfiyya MN, McCullough JE, Mitchell L, Dean LS, Lipsky MS. Adequacy of diabetes care for older U.S. rural adults: a cross-sectional population based study using 2009 BRFSS data. BMC Public Health 2011 Dec 16;11:940 [FREE Full text] [doi: 10.1186/1471-2458-11-940] [Medline: 22177279]

10. Chen X, Orom H, Hay JL, Waters EA, Schofield E, Li Y, et al. Differences in Rural and Urban Health Information Access and Use. J Rural Health 2019 Jun;35(3):405-417 [FREE Full text] [doi: 10.1111/jrh.12335] [Medline: 30444935]

11. O'Connor A, Wellenius G. Rural-urban disparities in the prevalence of diabetes and coronary heart disease. Public Health 2012 Oct;126(10):813-820. [doi: 10.1016/j.puhe.2012.05.029] [Medline: 22922043]

12. Siminerio LM, Piatt G, Zgibor JC. Implementing the chronic care model for improvements in diabetes care and education in a rural primary care practice. Diabetes Educ 2005;31(2):225-234. [doi: 10.1177/0145721705275325] [Medline: 15797851]

13. Skillman SM, Andrilla CHA, Patterson DG, Fenton SH, Ostergard SJ. Health information technology workforce needs of rural primary care practices. J Rural Health 2015;31(1):58-66. [doi: 10.1111/jrh.12081] [Medline: 25066067]

14. Jessee B, Rutledge C. Effectiveness of nurse practitioner coordinated team group visits for type 2 diabetes in medically underserved Appalachia. J Am Acad Nurse Pract 2012 Dec;24(12):735-743. [doi: 10.1111/j.1745-7599.2012.00764.x] [Medline: 23190131]

15. Zgibor JC, Gieraltowski LB, Talbott EO, Fabio A, Sharma RK, Hassan K. The association between driving distance and glycemic control in rural areas. J Diabetes Sci Technol 2011 May 01;5(3):494-500 [FREE Full text] [doi: 10.1177/193229681100500304] [Medline: 21722565]

16. Hale NL, Bennett KJ, Probst JC. Diabetes care and outcomes: disparities across rural America. J Community Health 2010 Aug;35(4):365-374. [doi: 10.1007/s10900-010-9259-0] [Medline: 20386968]

17. Office of Rural Health Annual Report Thrive 2018. US Department of Veterans Affairs. URL: https://www.ruralhealth.va.gov/ docs/ORH Thrive2018 FINAL 508.pdf [accessed 2021-11-04]

18. Rural Veterans Health Care Atlas. US Department of Veterans Affairs. URL: https://www.ruralhealth.va.gov/docs/atlas/ CHAPTER_00_Introduction.pdf [accessed 2021-11-04]

19. Powers MA, Bardsley J, Cypress M, Duker P, Funnell MM, Fischl AH, et al. Diabetes Self-management Education and Support in Type 2 Diabetes. Diabetes Educ 2017 Feb;43(1):40-53. [doi: 10.1177/0145721716689694] [Medline: 28118121]

20. American Diabetes Association. 1. Improving Care and Promoting Health in Populations: Standards of Medical Care in Diabetes. Diabetes Care 2020 Jan;43(Suppl 1):S7-S13. [doi: 10.2337/dc20-S001] [Medline: 31862744]

21. Kaufman N, Ferrin C, Sugrue D. Using Digital Health Technology to Prevent and Treat Diabetes. Diabetes Technol Ther 2019 Feb;21(S1):S79-S94. [doi: 10.1089/dia.2019.2506] [Medline: 30785320]

22. Yu C, Bahniwal R, Laupacis A, Leung E, Orr M, Straus S. Systematic review and evaluation of web-accessible tools for management of diabetes and related cardiovascular risk factors by patients and healthcare providers. J Am Med Inform Assoc 2012;19(4):514-522 [FREE Full text] [doi: 10.1136/amiajnl-2011-000307] [Medline: 22215057]

23. Urowitz S, Wiljer D, Dupak K, Kuehner Z, Leonard K, Lovrics E, et al. Improving diabetes management with a patient portal: a qualitative study of diabetes self-management portal. J Med Internet Res 2012 Nov 30;14(6):e158 [FREE Full text] [doi: 10.2196/jmir.2265] [Medline: 23195925]

24. Shimada S, Petrakis B, Rothendler J, Zirkle M, Zhao S, Feng H, et al. An analysis of patient-provider secure messaging at two Veterans Health Administration medical centers: message content and resolution through secure messaging. J Am Med Inform Assoc 2017 Sep 01;24(5):942-949 [FREE Full text] [doi: 10.1093/jamia/ocx021] [Medline: 28371896]

25. Robinson SA, Zocchi MS, Netherton D, Ash A, Purington CM, Connolly SL, et al. Secure Messaging, Diabetes Self-management, and the Importance of Patient Autonomy: a Mixed Methods Study. J Gen Intern Med 2020 Oct;35(10):2955-2962 [FREE Full text] [doi: 10.1007/s11606-020-05834-x] [Medline: 32440998]

26. Chung S, Panattoni L, Chi J, Palaniappan L. Can Secure Patient-Provider Messaging Improve Diabetes Care? Diabetes Care 2017 Oct;40(10):1342-1348. [doi: 10.2337/dc17-0140] [Medline: 28807977] 
27. Shimada SL, Allison JJ, Rosen AK, Feng H, Houston TK. Sustained Use of Patient Portal Features and Improvements in Diabetes Physiological Measures. J Med Internet Res 2016 Jul 01;18(7):e179 [FREE Full text] [doi: 10.2196/jmir.5663] [Medline: 27369696]

28. Drake C, Zhang Y, Chaiyachati KH, Polsky D. The Limitations of Poor Broadband Internet Access for Telemedicine Use in Rural America: An Observational Study. Ann Intern Med 2019 Sep 03;171(5):382-384. [doi: 10.7326/M19-0283] [Medline: 31108509]

29. Sun R, Burke LE, Saul MI, Korytkowski MT, Li D, Sereika SM. Use of a Patient Portal for Engaging Patients with Type 2 Diabetes: Patterns and Prediction. Diabetes Technol Ther 2019 Oct;21(10):546-556. [doi: 10.1089/dia.2019.0074] [Medline: $\underline{31335206]}$

30. Greenberg AJ, Haney D, Blake KD, Moser RP, Hesse BW. Differences in Access to and Use of Electronic Personal Health Information Between Rural and Urban Residents in the United States. J Rural Health 2018 Feb;34 Suppl 1:s30-s38 [FREE Full text] [doi: 10.1111/jrh.12228] [Medline: 28075508]

31. Hogan TP, Nazi KM, Luger TM, Amante DJ, Smith BM, Barker A, et al. Technology-assisted patient access to clinical information: an evaluation framework for blue button. JMIR Res Protoc 2014 Mar 27;3(1):e18 [FREE Full text] [doi: 10.2196/resprot.3290] [Medline: 24675395]

32. Stewart MT, Hogan TP, Nicklas J, Robinson SA, Purington CM, Miller CJ, et al. The Promise of Patient Portals for Individuals Living With Chronic Illness: Qualitative Study Identifying Pathways of Patient Engagement. J Med Internet Res 2020 Jul 17;22(7):e17744 [FREE Full text] [doi: 10.2196/17744] [Medline: $\underline{\text { 32706679] }}$

33. Hart LG, Larson EH, Lishner DM. Rural definitions for health policy and research. Am J Public Health 2005 Jul;95(7):1149-1155. [doi: 10.2105/AJPH.2004.042432] [Medline: 15983270]

34. Kravitz RL, Bell RA, Franz CE. A taxonomy of requests by patients (TORP): a new system for understanding clinical negotiation in office practice. J Fam Pract 1999 Nov;48(11):872-878. [Medline: 10907624]

35. Schmitt A, Gahr A, Hermanns N, Kulzer B, Huber J, Haak T. The Diabetes Self-Management Questionnaire (DSMQ): development and evaluation of an instrument to assess diabetes self-care activities associated with glycaemic control. Health Qual Life Outcomes 2013 Aug 13;11:138 [FREE Full text] [doi: 10.1186/1477-7525-11-138] [Medline: 23937988]

36. Rosendaal FR, Cannegieter SC, van der Meer FJM, Briët E. A method to determine the optimal intensity of oral anticoagulant therapy. Thromb Haemost 1993 Mar 01;69(3):236-239. [Medline: 8470047]

37. Hayes A. Introduction to Mediation, Moderation, and Conditional Process Analysis: A Regression-Based Approach (2nd edition). New York, NY: Guilford Press; 2017.

38. Hayes AF. Partial, conditional, and moderated moderated mediation: Quantification, inference, and interpretation. Communication Monographs 2017 Aug 03;85(1):4-40. [doi: 10.1080/03637751.2017.1352100]

39. Lepard MG, Joseph AL, Agne AA, Cherrington AL. Diabetes self-management interventions for adults with type 2 diabetes living in rural areas: a systematic literature review. Curr Diab Rep 2015 Jun;15(6):608 [FREE Full text] [doi:

10.1007/s11892-015-0608-3] [Medline: 25948497]

40. Greenwood DA, Gee PM, Fatkin KJ, Peeples M. A Systematic Review of Reviews Evaluating Technology-Enabled Diabetes Self-Management Education and Support. J Diabetes Sci Technol 2017 Sep;11(5):1015-1027 [FREE Full text] [doi: 10.1177/1932296817713506] [Medline: 28560898]

41. O'Shea A, Batten A, Hu E, Augustine M, Kaboli P. Association between Secure Messaging and Primary Care Face - to - Face Visits and Phone Visits. Health Serv Res 2020 Aug 20;55(S1):41-41. [doi: 10.1111/1475-6773.13382]

42. Ross S, Benavides-Vaello S, Schumann L, Haberman M. Issues that impact type-2 diabetes self-management in rural communities. J Am Assoc Nurse Pract 2015 Nov;27(11):653-660. [doi: 10.1002/2327-6924.12225] [Medline: 25776183]

43. Heyworth L, Kirsh S, Zulman D, Ferguson J, Kizer K. Expanding access through virtual care: The VA's early experience with Covid-19. NEJM Catalyst Innovations in Care Delivery 2020 Jul 01;1(4) [FREE Full text]

44. Myers US, Birks A, Grubaugh AL, Axon RN. Flattening the Curve by Getting Ahead of It: How the VA Healthcare System Is Leveraging Telehealth to Provide Continued Access to Care for Rural Veterans. J Rural Health 2021 Jan;37(1):194-196 [FREE Full text] [doi: 10.1111/jrh.12449] [Medline: 32282955]

45. Hsiao V, Chandereng T, Lankton RL, Huebner JA, Baltus JJ, Flood GE, et al. Disparities in Telemedicine Access: A Cross-Sectional Study of a Newly Established Infrastructure during the COVID-19 Pandemic. Appl Clin Inform 2021 May;12(3):445-458. [doi: 10.1055/s-0041-1730026] [Medline: 34107542]

\section{Abbreviations}

$\mathbf{A}_{1 \mathrm{c}} \%$ TIC: percentage of time in control over the course of the year based on hemoglobin $\mathrm{A}_{1 \mathrm{c}}$ measurements

CDW: Corporate Data Warehouse

DSMQ: Diabetes Self-Management Questionnaire

$\mathbf{H b A}_{1 \mathbf{c}}$ : hemoglobin $\mathrm{A}_{1 \mathrm{c}}$

MHV: My HealtheVet

RUCA: Rural-Urban Commuting Areas

SM: secure messaging 
TIC: time in control

VA: Veterans Affairs

VHA: Veterans Health Administration

Edited by $G$ Eysenbach; submitted 22.07.21; peer-reviewed by $R$ Sun, A Dalal; comments to author 13.08.21; revised version received 07.10.21; accepted 07.10.21; published 19.11.21

Please cite as:

Robinson SA, Netherton D, Zocchi M, Purington C, Ash AS, Shimada SL

Differences in Secure Messaging, Self-management, and Glycemic Control Between Rural and Urban Patients: Secondary Data Analysis

JMIR Diabetes 2021;6(4):e32320

URL: https://diabetes.jmir.org/2021/4/e32320/

doi: $\underline{10.2196 / 32320}$

PMID:

(CStephanie A Robinson, Dane Netherton, Mark Zocchi, Carolyn Purington, Arlene S Ash, Stephanie L Shimada. Originally published in JMIR Diabetes (https://diabetes.jmir.org), 21.11.2021. This is an open-access article distributed under the terms of the Creative Commons Attribution License (https://creativecommons.org/licenses/by/4.0/), which permits unrestricted use, distribution, and reproduction in any medium, provided the original work, first published in JMIR Diabetes, is properly cited. The complete bibliographic information, a link to the original publication on https://diabetes.jmir.org/, as well as this copyright and license information must be included. 